\title{
Professores em formação continuada: narrativas da atividade docente de estudo e a da aprendizagem da docência ${ }^{1}$
}

Teachers in continuing education: narratives of teaching activity upon the study of teaching and learning

Leila Adriana Baptaglin*

Universidade Federal de Roraima

Gislaine Aparecida Rodrigues da Silva Rossetto**

Universidade Federal de Santa Maria

Doris Pires Vargas Bolzan***

Universidade Federal de Santa Maria

Resumo A formação continuada de professores constitui-se em um processo complexo e de dimensões que ultrapassam a elaboração e execução de normativas legais. Este estudo apresenta nossa compreensão sobre a atividade docente de estudo, pautada nos estudos de Isaia (2006), na formação e atuação de professores da Educação Básica e sua contribuição para os processos de aprendizagem da docência (ISAIA, 2004 e 2006; BOLZAN, 2004, 2006, 2008, 2009, 2010). Nosso objetivo é identificar e compreender onde e como a atividade docente de estudo, acontece na formação e atuação de professores da Educação Básica, e de que forma ela contribui para a aprendizagem da docência. A partir das narrativas, identificamos que os elementos da atividade docente de estudo não se articulam, em sua completude, nos diferentes momentos da prática pedagógica.

PALAVRas-CHAVE: Formação Continuada de Professores, Aprendizagem Docente, Atividade Docente de Estudo, Educação Básica.

Abstract The continuing education of teachers is in a complex process and dimensions that go beyond the development and implementation of legal regulations. This study presents our understanding of teaching activity study, based on studies of Isaia (2006), the formation and action of teachers of Basic Education and their contribution to the learning processes of teaching (Isaia, 2004 and 2006; BOLZAN, $2004,2006,2008,2009,2010)$. Our goal is to identify and understand where and how the study of teaching activity takes place in the formation and action of teachers of basic education and how it contributes to the learning of teaching of these teachers. From the narratives, we identified that the elements of teaching study did not articulate entirety with themselves at different times of the pedagogical practice.

KEYWORDS: Continuing Education of Teachers, Teacher Learning, Teacher Activity Study, Basic Education. 


\section{Introdução}

A formação continuada de professores constitui-se em um processo complexo e possui dimensões que ultrapassam a elaboração e execução de normativas legais, assim como investimentos de grande porte. Consideramos que, para ser possível sua concretização e sua análise, ela requer muito mais do que o diagnostico das possíveis lacunas, na formação inicial ou mesmo nos dilemas e os desafios provenientes do cotidiano da escola. Trazê-la para a pauta de discussão suscita que a repensemos como uma ação que leva em conta a aprendizagem docente, considerando as necessidades e os interesses dos sujeitos envolvidos, e suas condições de trabalho.

Compreendemos por formação continuada a formação que acontece ao longo da trajetória profissional do professor que busca estar sempre aprendendo e reaprendendo de modo a contribuir para o seu constante desenvolvimento profissional. Dessa forma, ela está orientada para a ideia de uma constante postura e disposição do sujeito em aprender a aprender, ou seja, a uma conduta docente de aprendizagem permanente (GARCÍA, 1999). A partir desse entendimento compreendemos que os termos formação continuada e formação permanente não se diferenciam.

No âmbito da Educação Básica, os processos formativos são exaustivamente discutidos, entretanto poucas alternativas de soluções práticas são evidenciadas, e, quando o são, tratam, de situações isoladas (SANTOS, 2011). Pensar na formação continuada e, consequentemente, na aprendizagem docente dos professores desse nível de ensino é imprescindível, tendo em vista a baixa qualidade do ensino em todo o país, sinalizada nos dados do Índice de Desenvolvimento da Educação Básica (IDEB, 2012) e, nos informativos do Relatório de Monitoramento de Educação para Todos (UNESCO, 2008). Entretanto, vale ressaltar que a melhora dessa qualidade não depende exclusivamente dos diferentes processos de formação de professores, mas precisamente passa por eles. Nossa compreensão é a de que "[...] as situações enfrentadas atualmente na educação brasileira têm um mosaico de causas, que apresentam muitos fatores a serem problematizados e enfrentados pelos professores da educação básica" (SANTOS, 2011, p. 34-35). Um dos fatores que contribuiriam para uma melhoria da educação é o incentivo e a garantia de espaços e tempos formativos organizados e sistematizados a partir das necessidades e interesses oriundos dos próprios professores, isto é, das necessidades formativas apresentadas pelos sujeitos que as vivenciam.

Consideramos que, a tomada de consciência, pelos professores de suas necessidades de aprendizagem, é de fundamental importância para sua autoformação, uma vez que, se o sujeito não se sentir implicado nesse processo formativo, em seus modos de aprender a aprender, dificilmente acontecerá alguma mudança seja no âmbito pessoal, e ou seja no profissional. É nesta perspectiva que buscamos compreender onde e como a atividade docente de estudo acontece, na formação e atuação de professores da Educação Básica, e de que forma ela contribui para a aprendizagem da docência destes sujeitos.

\section{Dimensões investigativas: contando um pouco da pesquisa que origina nossas discussões}

Este trabalho é um recorte do projeto de pesquisa "Aprendizagem Docente e Processos Formativos: movimentos construtivos da professoralidade na educação 
básica e superior", o qual foi desenvolvido pelo Grupo de Estudos e Pesquisas Formação de Professores e Práticas Educativas: Educação Básica e Superior (GPFOPE), da Universidade Federal de Santa Maria (UFSM). O projeto visa compreender os movimentos produzidos na formação docente dos professores atuantes tanto na Educação Básica, quanto no Ensino Superior, ao aprofundar temas que envolvem a sua constituição. Os estudos que sustentam a investigação em pauta são: Garcia (1999), Bolzan (2002, 2010); Bolzan e Isaia (2006; 2007); Isaia e Bolzan (2004; 2005; 2007); Isaia (2006); Vygotski (1993; 1994); Leontiev (1984); Davídov e Márkova, (1987); Ferry (2004); entre outros.

A abordagem qualitativa-narrativa de cunho sociocultural (BOLZAN, 2006; FREITAS, 2002; CONELLY; CLANDININ, 1995) pauta a dinâmica investigativa da citada pesquisa e fundamenta os achados a partir dos ditos/falas dos sujeitos pesquisados. Esta abordagem, segundo Bolzan (2006), se embasa na construção coletiva dos sujeitos e leva em conta as mediações socioculturais a partir das quais os mesmos se constituem.

O desenvolvimento investigativo passou por três etapas: na primeira, foram realizadas entrevistas com professores da Educação Básica; na segunda, com professores de Educação Superior; e na terceira e última, com acadêmicos em Formação Inicial do curso de Pedagogia diurno da UFSM. O instrumento utilizado para coletar os achados foram entrevistas organizadas a partir de tópicos guias, cada qual com questões norteadoras que orientaram o diálogo entre o pesquisador e o sujeito entrevistado.

As narrativas que emergiram das entrevistas passaram por um processo de leitura e de análise, a partir do qual foram assinaladas as recorrências. Estas, por sua vez, foram agrupadas conforme o objetivo e o referencial teórico da pesquisa. A partir das recorrências foram elaborados quadros com conjuntos de excertos narrativos que apresentavam as recorrências. O conjunto destas deram origem aos elementos categoriais que, por sua vez, foram reagrupados constituindo os eixos de análise. Estes eixos constituíram-se, na primeira tentativa de organização das dimensões categoriais, as quais consideramos importantes, pois nos auxiliaram na construção de conceitos macros que culminaram nas categorias de análise da pesquisa. Compreendemos que a categoria de análise, nesta perspectiva metodológica, tem o potencial de "explicar, de conceituar o fenômeno analisado. Por essa razão, mais uma vez, se faz imprescindível o movimento de retomada dos objetivos da pesquisa, bem como à base teórica da investigação empreendida" (ROSSETTO, 2013, p. 127).

A partir deste procedimento metodológico, foram estruturadas as seguintes categorias: aprendizagem docente; trabalho pedagógico e atividade docente de estudo (ISAIA, 2006; BOLZAN, 2009, 2010, 2011, 2012). Além destas categorias, foram destacados dois movimentos delas decorrentes: alternância pedagógica e resiliência docente (FERRY, 2004; BOLZAN, 2010).

Para este ensaio, utilizamos os excertos das narrativas de 11 professoras da rede de ensino de Educação Básica de Santa Maria/RS, sendo: 1 professora da Educação Infantil, 6 professoras dos Anos Iniciais, 3 professoras dos Anos Finais do Ensino Fundamental e 1 professora do Ensino Médio. O recorte, que apresentamos, tem como objetivo identificar e compreender onde e como a atividade docente de estudo acontece, na formação e atuação de professores da Educação Básica, e de que forma ela contribui para a aprendizagem da docência desses professores. 
Nessa perspectiva, focaremos nossas discussões nas interlocuções estabelecidas entre as categorias "atividade docente de estudo" e "aprendizagem docente" por considerarmos que elas se complementam e dialogam com a formação continuada dos professores da Educação Básica.

\section{Atividade de estudo, atividade docente de estudo e aprendizagem docente: primeiras aproximações teóricas}

Para Davídov e Márkova (1987), atividade de estudo implica a produção de algo que tenha sentido para o sujeito que a realiza, mobilizada por uma necessidade; por essa razão é essencial que o sujeito compreenda o(s) objetivo(s) da tarefa que efetua. Constitui-se em uma estrutura composta por três elementos: tarefa(s) de estudo, ações de estudo e autoavaliação. A tarefa de estudo consiste no momento em que o sujeito compreende o objetivo da tarefa a ser realizada, e assume para si a responsabilidade da tarefa. Disso depende o quanto se sente motivado para sua efetivação e, consequentemente, o desenvolvimento do seu pensar autônomo. As ações de estudo compreendem os aspectos teóricos, ações em nível cognitivo do sujeito a serem efetivadas durante a atividade de estudo. $\mathrm{E}$, por fim, temos a autoavaliação, que consiste na capacidade de o sujeito planejar o que irá realizar antes de iniciar o trabalho, e que será efetivada durante e ao final, dos resultados que emergiram desse processo (DAVÍDOV; MÁRKOVA, 1987).

A partir do conceito de Atividade de Estudo, Isaia (2006, p. 377) elabora o conceito de atividade docente de estudo compreendida como um "mecanismo complexo utilizado para acionar o processo de aprender a ser professor". Assim como na atividade de estudo, a atividade docente de estudo apresenta três componentes que se interligam: a tarefa educativa, ações e operações e autorregulação.

$\mathrm{Na}$ tarefa educativa, o professor necessita compreender a tarefa a ser efetivada. $\mathrm{O}$ segundo componente são as ações e operaçôes. As ações referem-se aos aspectos teóricos e são caracterizadas por serem intencionais, no sentido de ser capaz de responder a "o que deve ser realizado?" e, também respondem a "como e de que modo posso executar a ação?"; e as operações caracterizam-se como os aspectos operacionais / práticos da execução de cada ação; é o "fazer" da ação (ROSSETTO, 2011). Na autorregulação da própria tarefa, o docente tem a oportunidade de rever e refazer seus caminhos no momento em que avalia os objetivos alcançados (ISAIA, 2006).

Estas conceituações tornam-se necessárias para discutirmos a interlocução entre as categorias de "atividade docente de estudo" e "aprendizagem docente". Assim, compreendemos por aprendizagem da docência, um processo inter e intrapessoal que envolve a aquisição de conhecimentos, saberes e fazeres próprios do magistério em diversos campos de atuação (ISAIA, 2006). É caracterizada pela tomada de consciência, por parte do professor, de seu inacabamento e de seu papel simultâneo de ensinante e aprendente, e, por fim, do reconhecimento de sua necessidade da reflexão acerca as produção da sua docência (BOLZAN, 2010). A aprendizagem docente acontece a partir de uma estrutura que envolve:

[...] o processo de apropriação, em sua dimensão interpessoal e intrapessoal; o impulso que a direciona, representados por sentimentos que indicam sua finalidade geral; o estabelecimento de objetivos 
específicos, a partir da compreensão do ato educativo e, por fim, as condições necessárias para a realização dos objetivos traçados, envolvendo a trajetória pessoal e profissional dos professores, bem como o percurso trilhado por suas instituições. (ISAIA, 2006)

Vale ressaltar que consideramos a atividade docente de estudo como ponto desencadeador da aprendizagem da docência, visto que se complementam, relacionando-se, de forma a influenciar a formação continuada das professoras da Educação Básica, sujeitos desse estudo.

\section{Narrativas das professoras da Educação Básica: tecendo as tramas da atividade docente de estudo e da aprendizagem da docência ${ }^{2}$}

Compreendemos a aprendizagem da docência como um processo inter e intrapessoal (ISAIA; BOLZAN, 2004), instigado pelas necessidades e motivos suscitados pela própria atividade pedagógica. É, nessa perspectiva, que a aprendizagem da docência é desencadeada pela atividade docente de estudo, ou seja, quando o professor se sente estimulado e desafiado a procurar respostas às situações-problemas de seu cotidiano pedagógico. Isto poder ser ilustrado pelas narrativas que seguem:

Então quando eu estou em sala de aula, com os pequenos assim [...] é tanta coisa que a gente aprende de novo, porque eles exigem muito da gente, eles estão anos luz, como a gente diz, eles estão sempre buscando, eles são instigados, então a gente está sempre construindo coisas novas, porque o processo de aprender é justamente isso, construir conceitos que sejam significativos pra vida daquele sujeito, e uma vez que isso é construído, jamais é esquecido.[...] Enquanto eu estou ensinando, eu estou aprendendo, e o processo de ensinar é justamente isso. (TA/Anos Iniciais)

Ah! Eu adoro estar em contato com os alunos, porque através do meu ensinar que eu aprendo com eles e os desafios diários deles, através das experiências, através do dia a dia que a gente vai se realizando como profissional. (DI/Anos Finais)

O fato de as crianças exigirem dos professores "coisas novas", as quais podem ser configuradas em atividades pedagógicas ou mesmo questionamentos e/ou curiosidades, cria, para esses docentes, necessidades de buscarem possíveis respostas para tais situações-problemas. São esses desafios diários que motivam os professores, muitas vezes, a se realizarem como profissionais. Observamos, nesses ditos, a coexistência de sua função de ensinante e aprendente e, especialmente do aspecto do inacabamento no processo de aprender a ser professor, conforme também se evidencia nas narrativas que seguem:

O aprender também é um desafio porque tu não aprende só nos livros, tu aprende na tua vivência diária. Então o aprender te questionar, é enriquecer, é poder te [...] poder ensinar o que tu [...] o conhecimento que tu tem e tu aprende muito com o aluno, quando como tu ensina tu aprende [...] é naquela troca. (DI/Anos Finais)

[...] as leituras do grupo que me ajudam muito a refletir, a pensar sobre tudo o que a gente pratica no dia a dia, a teoria é algo muito importante $[. .$.$] discutir com pessoas de diferentes níveis de$ 
aprendizagem, sejam acadêmicos, sejam mestrandos, doutorandos, professores da Universidade. (SA/Anos Iniciais)

Eu acho que a gente está a vida inteira aprendendo com fatos que acontecem, quando eu comecei como professora eu não era o que eu sou hoje né, eu não agia como eu ajo hoje. (RO/Anos Finais)

Considerando que o sujeito aprende ao longo de sua trajetória profissional, à medida que toma consciência do seu inacabamento, nos insita a pensar em outro aspecto da aprendizagem da docência, que é o de seu reconhecimento sobre a necessidade de refletir acerca da produção da sua docência. Isto significa estar constantemente atento aos modos de ser e fazer na profissão.

Eu acho que nós como professores e educadores a gente pensa e reflete. Eu acho que cada um que está aqui sabe que trabalho está realizando, como que esse trabalho está sendo entendido pelo aluno, como está participando. O que falta é eu me desacomodar e buscar novas metodologias, novas formas de apresentar esse trabalho. (RO/Anos Finais)

Pensar, acho que está muito ligado à ação. Eu costumo sempre pensar muito, assim oh, pensar, analisar e preparar e, às vezes até ensaio em casa, assim, uma atividade nova com as gurias ou comigo mesmo pra ver se vai dar certo porque o pensar está muito relacionado com a ação do dia a dia, tu tem que pensar antes e depois. (ED/ Anos Iniciais)

Eu acho assim oh, que o professor, todo o professor tem que chegar em casa e refletir sobre a sua aula. Tem que pensar, o que é que eu fiz, o que deu certo, o que é que poderia ter sido melhor né, o que é que eu posso fazer para amanhã, ou, quem sabe num próximo momento, aquilo que eu fiz e que não foi tão bom, mas... ficar melhor. (LU/Educação Infantil)

Emerge, dessas falas, a preocupação que mobiliza as professoras a buscar formas de organizar espaços de reflexão sobre sua prática pedagógica. Consideramos que esta busca é uma característica inerente à categoria da aprendizagem da docência e, também, nos lembra o terceiro elemento estruturante da atividade docente de estudo, a autorregulação, como também sinalizam as seguintes narrativas:

[...] a cada final de aula, por mais cansada que eu esteja eu chego em casa e sento pra pensar: bom, como é que foi a aula de hoje? Eu tinha qual objetivo pra hoje? Porque isso eu deixo muito claro no meu planejamento, tenho os meus objetivos assim [...] qual é o meu objetivo com esse projeto, ou com a aula de hoje, pra aula dessa semana? Aí eu sento e penso: bom, eu atingi aquele objetivo, o que não foi legal hoje, e o que foi legal hoje? (TA/Anos Iniciais)

Mas assim reflexões diárias muitas vezes a gente não consegue fazer [...]. Seria o ideal [...] eu faço mais semanal mesmo, não vou te mentir, que eu faço diária, por que a gente não consegue fazer. Deveria fazer. Mas a gente não consegue. É corrido e outra, a coordenação me toma muito tempo. Eu estou na sala de aula e tem gente me chamando. Então não é fácil mesmo. Deveria ter mais tempo, mas a gente não tem então a gente vai se adaptando assim. Mas semanal a gente consegue. (LU/Educação Infantil) 
No momento da autorregulação da tarefa educativa, o professor revê os caminhos que percorreu à medida em que avalia os objetivos alcançados. Esse é um processo de reflexão sobre sua prática, dinâmica que permite o sujeito autorregularse. Porém, não basta somente ser capaz de realizar a autorregulação da tarefa, como podemos observar na segunda narrativa, urge a necessidade de tempo e espaço institucionalizado e lugar para que o pensamento reflexivo seja exercitado. Vale ressaltar que compreendemos por lugar "[...] o espaço preenchido, não desordenadamente, mas a partir de significados de quem o ocupa" (CUNHA, 2010, p. 54), caso contrário o sujeito não alcança os objetivos e as expectativas a que se propõe.

Quanto aos próximos elementos da atividade docente de estudo, as açôes e as operações, percebemos que as professoras tendem a ficar no nível das operações, ou seja, na execução do que se refere a sua prática pedagógica. Nessa etapa, costuma-se responder a "como, de que modo posso executar a ação". E essas respostas, capazes de acionar o processo de aprender a ser professor geralmente são oriundas das situações práticas do cotidiano escolar. São modos de pensar que emergem do "aqui e agora", cuja necessidade é solucionar problemas imediatos, ou seja, "soluções" paliativas e mecanicistas. Nos excertos que seguem, evidenciamos exemplos de modos de executar ações pedagógicas que sinalizam um predomínio de operações:

Minhas colegas me ajudam muito para essa aprendizagem e os alunos fazem a gente aprender. Cada turma, tu trabalhas de forma diferente, porque as vivencias dos alunos são diferentes, isso produz aprendizagem, essa multiplicidade de entendimentos e a literatura dá espaço para isso, porque tu trabalhas muito com a argumentação, com as subjetividades. (MA/Anos Finais)

Eu não sigo assim uma teoria. Eu tenho assim, gosto muito do Piaget, eu vou pegando o que elas tem de melhor, digamos assim, o que eu acho que naquele momento, para aquele conteúdo. $\mathrm{O}$ que cada uma tem de bom assim, a gente vai tentando. A gente vai adequando aquilo para os conteúdos que tem que desenvolver, para os temas no caso $[. .$.$] , a gente vai tentando adequar. (LU/Educação Infantil)$

Nós temos já na escola o plano anual, e como somos duas professoras nós nos reunimos pra trabalhar a mesma coisa na mesma época e lá na minha escola do município, praticamente a gente define a ordem do nosso plano pelos jogos. Claro, além daquele básico nosso do início do ano da retomada da formação, então mais ou menos a gente vai organizando, então quando a gente vê que necessita de alguma coisa que ficou a gente se reúne eu e ela, a gente retoma e faz e é bem aberto. (NE/Anos Iniciais)

Considerando a incipiência das ideias é possível inferir que a ação, nas atividades pedagógicas desenvolvidas por essas professoras, ainda se apresenta de forma embrionária, posto que são evidenciadas lacunas com relação aos aspectos teóricos capazes de justificar e de sustentar os modos como podem executar as ações realizadas pelas professoras. Isto também pode ser visto nas narrativas a seguir:

[...] eu acredito que toda ação deve vir de um pensar inicial, muitas vezes a gente até não faz né, a ação vem solta, mas toda ação que vem solta... tu não tem um bom resultado [...]Tu precisa pensar [...] pra poder agir daquela forma, se não ela fica solta, ela fica no ar e $[\ldots]$ não atinge o teu objetivo [...]. (NE/Anos Iniciais) 
O pensar, eu acho que tu tem que pensar antes de agir. Se tu tem algum trabalho, tu tem que ter o raciocínio, tu tem que ter o teu pensamento pra ti poder agir. Eu penso assim, que os dois caminham juntos né. (DI/Anos Finais)

Mencionamos, anteriormente, a necessidade de lugares institucionalizados para a efetivação da atividade docente de estudo, no momento de reflexão individual e, até mesmo, coletiva. Observamos, em algumas falas, indicadores de momentos formativos:

A gente faz encontros de reuniões pedagógicas, a gente faz encontro de autoajuda e lê obras e depois discute [...]. (ED/Anos Iniciais)

Quando eu comecei aqui era uma dificuldade muito grande, era um grupo bem conteudista, só se preocupavam com isso, daí eu comecei fazer... nós tínhamos estudos todas as quartas-feiras e todos estudos voltados nesse sentido, do trabalho coletivo, da interdisciplinaridade e nós conseguimos agora um grupo bem unido, trabalhando nisso [...]. (RO/Anos Finais)

[...] eu acho que o contato com o grupo é essencial, ler, ter o contato com outras pessoas, ter essa relação assim [...] de discutir, mesmo que a temática não seja nova, sempre haverá algo para refletir, então eu estou sempre procurando bibliografias que possam alicerçar a minha prática, principalmente bibliografias referentes à formação de professores. (SI/Anos Iniciais)

Evidenciamos, por meio destas narrativas, que, para preencher as lacunas na formação docente, as professoras buscam a participação em grupos de estudo. Apresentam, questionam e procuram alternativas/possibilidades de organizar e desenvolver suas atividades dentro do cotidiano escolar. A necessidade de preencher estas lacunas torna-se o motivo da atividade docente de estudo, possibilitando a formação e o desenvolvimento da sua autonomia docente.

Nesse sentido, destacamos que a formação continuada e a participação em grupos de pesquisa e extensão são espaços fundamentais para que o professor esteja sempre aprendendo. E, é neste sentido que podemos dizer que as atividades docentes de estudo e a aprendizagem da docência estão imbricadas, posto que é, a partir da percepção dos motivos e das necessidades da tarefa, da realização de ações e operações e da autorregulação que as professoras aprendem o ofício da docência. Isso pode ser evidenciado nas falas das professoras quando dizem que

A partir das experiências que eu tenho, estamos falando aprender a docência, não é na academia que aprendo a ser docente, ela te possibilita enxergar coisas que tu não enxerga, mas essa aprendizagem se faz através de leituras, de busca, a academia me deu poucos subsídios, se eu tivesse que sair da Universidade e dar aula... Nossa! O exemplo é os estagiários que temos, eles não tem bagagem nenhuma. (SO/Ensino Médio)

Eu acho que é também uma mudança que tu internaliza aquele aprendizado, tu dispõe a aprender e, eu acho que tem que ter uma mudança, se tu aprender e não mudar alguma coisa é porque não aprendeu, sabe, eu acho que a aprendizagem tá muito ligada, assim, à mudança de comportamento, à mudança de estratégia pra vida, 
ah, pra ti te melhora, se tu não melhorar alguma coisa tu não aprende, eu acho. (ED/Anos Iniciais)

[...] quando comecei não tinha a formação apropriada né. Fui aprendendo trabalhando, acho que isso foi um ponto muito positivo, porque o que a gente aprendia, já testava e a gente via o que dava certo e o que não tinha dado [...] A prática é bem significativa pra gente, vai testando, vai vendo a teoria compreendendo as coisas na prática e entendendo melhor com as teorias que a gente vai aprendendo, vai relacionando, fazendo experiência. (ZE/Anos Iniciais)

Estas narrativas sinalizam a complexidade da docência e a implicação que a atividade docente de estudo tem em relação à aprendizagem desta. Destacamos, nesse conjunto de narrativas, a compreensão de inacabamento e a busca de uma continuidade formativa revelada pela tomada de consciência de que, nesse processo, os professores são ao mesmo tempo, ensinante e aprendente (BOLZAN, 2002). Assim, a ênfase na prática docente está assentada, em grande medida, nas experiências que se desdobram a partir de reflexões e de interações estabelecidas através dos acontecimentos e fatos reproduzidos na relação pedagógica, situações estas que são dinamizadas em espaços coletivos, em grupos de estudo, pesquisa, extensão e/ou em programas de formação continuada.

\section{Considerações finais}

Neste estudo, evidenciamos, a partir das análises das narrativas das professoras da Educação Básica, que a atividade docente de estudo é um fator preponderante na aprendizagem docente. Isto pode ser evidenciado nos momentos em que as docentes disseram sentir-se estimuladas e desafiadas a procurarem respostas às situações -problemas presentes em seu cotidiano pedagógico. Este estímulo e desafio constituíram-se em motivo para que elas pudessem pensar em formas de se organizarem para buscar soluções aos desafios que lhes eram apresentados.

No entanto, podemos considerar que a atividade docente de estudo ainda se apresenta de forma incipiente na proporção em que os seus elementos estruturantes (tarefa educativa, ações e operações e autorregulação) se apresentam de formas dispersas nos diferentes momentos das práticas pedagógicas das professoras. No que se refere à tarefa educativa, observamos, nas narrativas, que as professoras, em suas reflexões individuais ou coletivas, conseguem perceber as necessidades e os motivos da realização de sua tarefa, porém, nem sempre se comprometem na efetivação da mesma. Quanto às ações e operações, entendemos que as professoras que se comprometem com a tarefa educativa realizam-nas, mesmo que ainda de forma incipiente. No entanto, o que fica evidente é a realização de operações com o objetivo de solucionar problemas imediatos. Evidenciamos que, geralmente, há uma preocupação das docentes na busca de novos modos de fazer pedagógicos, no lugar de criação e [re], elaboração dos mesmos.

Quanto à autorregulação percebemos que os professores constantemente revisam e reavaliam suas práticas pedagógicas a partir de instrumentos como o diário de aula e os planejamentos cotidianos. Durante esses momentos de reflexões de sua prática pedagógica, observamos, nas vozes das docentes, a necessidade de atentar constantemente para a produção e formação contínua de sua docência, tendo em vista a tomada de consciência de que sua formação inicial é apenas o início de sua formação docente. 
Vale lembrar que o desenvolvimento da atividade docente de estudo possibilita a reflexão intra e interpessoal do docente que a experiencia, estimulando o seu processo de reorganização da prática pedagógica. Esse tipo de reflexão e de atividade é possível de ser realizada em espaço e tempo institucionalizado e lugar para que o pensamento reflexivo seja exercitado. Porém, a legitimação deste tempo e espaço não é suficiente, é preciso que os professores o constituam em lugar de formação docente, de modo a interagir com seus pares, compartilhando conhecimentos, experiências, bem como discutindo acerca de situações problemas provenientes tanto do grupo docente, quanto da comunidade educativa.

Concebemos que esse lugar precisa ser um espaço preenchido de sentidos e de significados para os sujeitos que o frequentam, pois disso depende boa parte da apreensão dos conhecimentos, por parte, no caso, dos docentes durante os momentos de formação continuada que lhes são oferecidos. Atribuir sentido e significado à formação continuada significa dizer que não estamos considerando apenas os aspectos cognitivos nesse processo de formação, mas também os aspectos afetivos e socioculturais do grupo de professores envolvidos.

Nesse sentido, concluímos dizendo que a constituição de um lugar de formação continuada é indispensável como forma de proporcionar aos professores a organização e a vivência da atividade docente de estudo. Consideramos que estes espaços (a participação em grupos de pesquisa e extensão) são essenciais para o desenvolvimento de sua autonomia intelectual e reflexão sobre a prática pedagógica, favorecendo, assim, a construção da docência.

À medida em que os professores se mobilizam para aprender a docência, envolvendo-se em atividades docentes de estudo, encontram sentido e significado para a realização de seus objetivos. Assim, ponderamos que a análise dos excertos das narrativas docentes traz, como contribuição, a necessidade da conquista de lugares (CUNHA, 2010) de formação institucionalizados, os quais são o ponto de partida para favorecer tanto o êxito das práticas pedagógicas quanto o êxito das metas traçadas no âmbito pessoal e legal, para a formação continuada dos docentes.

Referências

BOLZAN, D. P. V. Formação de Professores: construindo e compartilhando conhecimento. Porto Alegre: Mediação, 2002.

Verbetes. In: MOROSINI, M. (Org.). Enciclopédia de Pedagogia Universitária, Glossário II. Cap. X, 2006.

BOLZAN, D. P. V.; ISAIA, S. M. O conhecimento pedagógico compartilhado no processo formativo do professor universitário: reflexões sobre a aprendizagem docente. In: ANÂIS... do V Congresso Internacional de Educação-Pedagogias (entre) lugares e saberes, São Leopoldo, UNISINOS, 2007.

BOLZAN, D. P. V. Aprendizagem docente e processos formativos: movimentos construtivos da professoralidade na educação básica e superior. Projeto de Pesquisa Interinstitucional e integrado $\mathrm{CNPq} / \mathrm{PPGE} / \mathrm{CE} / \mathrm{UFSM}, 2009$.

Movimentos Construtivos da Docência/Aprendizagem: Tessituras Formativas. In: ANAIS do XV Endipe-Encontro Nacional de Didática e Prática de Ensino-Convergências e tensões no campo da formação e do trabalho docente: políticas e práticas educacionais, Belo Horizonte, 2010. 
BOLZAN, D. P. V.Aprendizagem docente e processos formativos: movimentos construtivos da professoralidade na educação básica e superior. Registro no GAP: 020117. Relatório Parcial de Pesquisa Interinstitucional e integrado CNPq/PPGE/CE/UFSM, 2011.

BOLZAN, D. P. V.; ISAIA, S. M. A. Aprendizagem docente na educação superior: construções tessituras da Professoralidade. Revista Educação. Porto Alegre: EDIPUCRS, 2006.

CUNHA, M. I. A docência como ação complexa. In: CUNHA, M. I. (Org.). Trajetórias e lugares de formação da docência universitária: da perspectiva individual ao espaço institucional. Araraquara, SP: Junqueira \& Marin; Brasília, DF: CAPES/ CNPq, 2010.

CONELLY, F. M.; CLANDININ, D.J. Relatos de Experiencia e Investigacion Narrativa. IN: LARROSA, J. et. al. Déjame que te cuente ensaios sobre narrativa y educación. Laertes, S. A. de Ediciones, 1995.

DAVÍDOV, V.; MÁRKOVA, A. El desarrollo del pensamiento em la edad escolar. In: DAVÍDOV, V.; SHUARE, M. (Orgs.) La psiologia evolutiva y pedogógica em la URSS. Moscou: Progresso, 1987 a.p. 173-193.

FERRY, G. Pedagogia de la formación. Buenos Aires: UBA. FFyl. Ediciones Novedades Educativas, 2004.

FREITAS, M. T. A. A abordagem sócio-histórica como orientadora da pesquisa qualitativa. Cadernos de Pesquisa, São Paulo, n. 116, p. 20-39, jul. 2002.

GARCIA, C. M. Formación del profesorado para el cambio educativo. Barcelona: Ediciones Universitarias de Barcelona, 1999.

ISAIA, S. M. A.; BOLZAN, D. P. V. Formação do professor do ensino superior: um processo que se aprende? Revista Educação. v. 29, n. 2, p. 121-133. UFSM. Santa Maria/RS, 2004.

. Aprendizagem Docente no Ensino Superior: construções a partir de uma rede de interações e mediações. In: UNIrevista. v. 1, n. 1. Anais... IV Congresso Internacional de Educação. UNISINOS. São Leopoldo. 2005.

. Construção da profissão docente/professoralidade em debate: desafios para a educação superior. In: CUNHA, M. I. (Org.). Reflexões e práticas em pedagogia universitária. Campinas: Papirus, 2007.

ISAIA, S. M. A. Aprendizagem Docente. In: MOROSINI, M. C. (Org.). Enciclopédia de Pedagogia Universitária, Glossário v. 2. Brasília: Instituto Nacional de Estudos e Pesquisas Educacionais Anísio Teixeira, 2006, p. 377.

LEONTIEV, A. N. Actividad, Conciencia, Personalidad. México: Editorial Cartago de México. 1984.

Portal do IDEB. Disponível em:<http://www.portalideb.com.br/>. Acesso em: 19 fev. 2012.

ROSSETTO, G. A. R. S. Atividade de estudo e autonomia intelectual no processo de aprendizagem da pesquisa. Qualificação de Projeto de Tese de Doutorado. Universidade Federal de Santa Maria (UFSM, RS). Programa de Pós-Graduação em Educação, 2011.

SANTOS, E. G. S. A dinâmica das ações extensionistas nos processos formativos de professores da educação básica: a tessitura de redes de relações entre escola e universidade. Qualificação de Projeto de Tese de Doutorado. Universidade Federal de Santa Maria (UFSM, RS). Programa de Pós-Graduação em Educação, 2011.

UNESCO. Relatório de Monitoramento de Educação para Todos. 2008. Disponível em: <http://unesdoc.unesco.org/images/0015/001592/159294 por.pdf>. Acesso em: 19 fev. 2012.

VYGOTSKI, L.S. A formação social da mente. São Paulo: Martins Fontes, 1994.

VYGOTSKI, L.S. Pensamento e Linguagem. São Paulo: Martins Fontes. 
Leila Adriana Baptaglin - Gislaine Aparecida Rodrigues da Silva Rossetto

Doris Pires Vargas Bolzan

Notas

${ }^{1}$ Este texto é uma ampliação do artigo apresentado em forma de painel no XVI Encontro Nacional de Didática e Prática de Ensino ENDIPE 2012.

${ }^{2} \mathrm{O}$ conjunto de excertos narrativos, bem como as categorias de análise apresentados ao longo do artigo foram extraídos do relatório de pesquisa APRENDIZAGEM DOCENTE E PROCESSOS FORMATIVOS: movimentos construtivos da professoralidade na Educação básica e Superior (2011), Registro GAP/CE: 025821, Produtividade em Pesquisa CNPq, de Doris Pires Vargas Bolzan.

* Professora Doutora da Universidade Federal de Roraima, Boa Vista, Roraima, Brasil.

** Professora Doutora pela Universidade Federal de Santa Maria, Santa Maria, Rio Grande do Sul, Brasil.

**** Professora Doutora da Universidade Federal de Santa Maria, Santa Maria, Rio Grande do Sul, Brasil.

\section{Correspondência}

Leila Adriana Baptaglin - Universidade Federal de Roraima, Reitoria. Avenida Capitão Ene Garcez - de 1985 ao fim - lado ímpar, Aeroporto, CEP: 69310000 - Boa Vista, Roraima - Brasil.

E-mail: leilaa251084@yahoo.com.br - gislainesilvarossetto@gmail.com - dbolzan19@gmail.com

Recebido em 31 de janeiro de 2013

Aprovado em 06 de novembro de 2013 